\title{
Discussion section
}

\section{Gender issues in computer-supported learning: what we can learn from the gender, science and technology literature}

\author{
Gwyneth Hughes \\ Centre for Learning Technologies Manager, University of East London \\ email: gwyneth@uel.ac.uk
}

This paper is a response to the article, 'Gender issues in computer-supported learning', in ALT-J 10 (I). I argue that the studies presented in the original paper could be enhanced by a more rigorous approach to gender that avoids universalizing identity, recognizes gender as a construction and which builds on previous research from gender, science and technology studies.

After the surge in research and literature on gender, science and technology in the 1980s and early 1990s, this paper brings us up to date with the growth in computer-supported learning (CSL), adding an extra dimension since computer technology is now a mode of delivery as well as a discipline under study. The evidence presented in this paper that a gender gap in access and IT literacy has been steadily closing during the 1990s seems to follow the closing of gender gaps in access and achievement in science and technology subjects in the UK (Arnot, David and Weiner, 1996). However, a closer look suggests that discriminatory practices that disadvantage females and males in CSL persist, and I suggest that there are some lessons which can be learned from the earlier gender, science and technology literature to avoid over-simplifying gender and assuming that undesirable gender effects can be easily overcome with good practice recommendations.

Firstly, research that universalizes gender by assuming that all females (or males) have common experiences is problematic. The authors acknowledge in their conclusion that 'issues of gender should not be treated in isolation from other factors', including educational backgrounds, but most of the studies reviewed in the paper did the opposite. A range of identities intersect with gender, such as ethnicity, class (Hughes, 2001), as well as sexuality and disability. Age (generation) was briefly mentioned in the article and is likely to be significant too. The case studies presented here are of IT and Web design courses and, consistent with European Union gender segregation statistics in computing and IT at 
higher education level (Rees, 2001), we know that the IT course is male-dominated. It would be useful to have this information for the Web design case study too. Despite the gender bias, the females performed well, but this is not necessarily a straightforward gender effect. Studies of other 'masculine' constructed disciplines such as physics and engineering have found that the women succeed, although they may have a difficult time, but this is because they are middle-class and academically advantaged female students (Thomas, 1990). Meanwhile, male underperformance in education in general has been linked to particular forms of (often class- and age-differentiated) masculinity which reject or play down academic study (Connell, 1995). Ethnicity may add more complexity as there is evidence that Black females are more willing to persevere with masculine areas of study than their white counterparts because of the career opportunities in an inequitable job market (Mirza, 1992; Hughes, 2001). Because of such differences between females, the two statements about girls' achievement given in the introduction are not necessarily contradictory - it depends on which girls are counted.

Secondly, and to add further complexity, there is a body of theory that views gender as a constructed rather than essential characteristic (for example, Davies, 1989), and this too is missing from the discussion. Rowan (2000) explains that it is not only differences between women, but differences, or conflicting identities, within women that produce the apparent gender differences in behaviour in CSL environments. It is not easy to construct a feminine identity while undertaking masculine activities, and female reporting of lack of confidence with Internet technology could be one way of dealing with internal gender conflict in a symbolically and culturally masculine environment of cyberspace. Thus, examining the context in which a gender identity is produced is very important. Essentialist approaches to gender have focused on learner deficiencies and tend to underplay the importance of educational and social factors on reproducing gender effects.

The authors do go some way towards acknowledging the importance of social context by stating that 'social issues such as ownership of technology are at the forefront of research and need further discussion'. Wacjman (1991) has pointed out that technology does not transform, but tends to reproduce, social relations. The authors implicitly support this approach in evidence from Herring that gender interactions and inequities in CSL reproduce those of traditional environments, and in their concern that the design of course management systems reproduces conventional didactic, rather than constructivist, learning environments. However, other links between gender identities and context are not made. It is not clear how far the gender effects reported in the paper arise from the use of technology as a learning tool, or because the technology is the subject of study, or indeed an inter-relationship between the two. Do the gender associations of the discipline make a difference; for example, are the gender issues of CMC (computer-mediated communication) different in sociology from computer studies?

Finally, recommendations for designers to construct well-moderated, flexible learning environments that are appropriate for a wide range of learners are valuable. However, the limited impact of initiatives such as WISE (Women into Science and Engineering) (Henwood, 1996) would suggest that there is no guarantee that gender divisions will readily disappear. Care must be taken that recommendations do not merely reinforce gender binaries by highlighting gender difference (as in the suggestions that males prefer games and females more collaborative activities). Although the audience for the ALT-C panel 
wanted solutions rather than more research on causes of gender inequalities, I would argue that quick fixes are unlikely to be found. Challenging the restrictions of gender binaries, without ignoring gender completely, is a tricky business and requires a sound appreciation of the complexities. Fortunately, the foundations for further exploration of gender and CSL already exist in an established body of related work.

\section{References}

Arnot, M., David, M. and Weiner, G. (1996), Educational Reforms and Gender Equality in Schools, Manchester: Equal Opportunities Commission.

Connell, R. (1995), Masculinities, Cambridge: Polity in association with Blackwell.

Davies, B. (1989), Frogs and Snails and Feminist Tales, Sydney: Allen \& Unwin.

Henwood, F. (1996), 'WISE Choices? Understanding occupational decision-making in a climate of equal opportunities for women in science and technology', Gender and Education, 8 (2), 119-214.

Hughes, G. (2001), 'Exploring the availability of student scientist identities within curriculum discourse: an anti-essentialist approach to gender inclusive science', Gender and Education, 13 (3), 275-90.

Mirza, H. (1992), Young Female and Black, London: Routledge.

Rees, T. (2001), 'Mainstreaming gender equality in science in the European Union: the ETAN Report', Gender and Education, 13 (3), 243-60.

Rowan, L. (2000), 'Human resource management, "flexible" learning and difference', in V. Jakupec and J. Garrick (eds), Flexible Learning Human Resource and Organisational Development: Putting Theory to Work, London: Routledge.

Thomas, K. (1990), Gender and Subject in Higher Education, Milton Keynes: Open University Press.

Wajcman, J. (1991), Feminism Confronts Technology, Cambridge: Polity. 